\title{
Genetically modified food from crops: progress, pawns, and possibilities
}

\author{
Xenia K. Morin
}

Published online: 14 August 2008

(C) Springer-Verlag 2008

\section{Introduction}

To most biochemist and chemists, and many farmers, the controversy over genetically modified (GM) food derived from crops ${ }^{1}$ seems puzzling. Why would anyone oppose GM food and animal feed (herein called GM food) produced using the tools of agricultural biotechnology? The answers behind this controversy are complicated and varied [1, 2]. The arguments against GM food range from the ethical and religious to concerns over inherent or potential risks to health and safety, and the environmental impact such technologies may have. Intellectual property rights and control over seeds by multinational corporations also bring out the ire of opposition groups [1]. The arguments in support of GM food range from the ethical and practical-how will we feed the world without GM food and animal feed? - to the scientific in which evidence is collected to address some of the opposition's concerns and to fill in gaps in our knowledge. Despite the concerns over GM food, the scope and number of GM crops planted each year continues to grow, and, interestingly, has made the adoption of GM seeds one of the most rapidly adopted farming technologies ever (Ref. [3] and Fig. 1). Therefore, it is reasonable to assume that agricultural biotechnology will continue to be adopted by farmers and thus the controversy will continue. It is also reasonable to assume

${ }^{1}$ Genetically modified food created by microorganisms and genetically modified animals and fish are beyond the scope of this article.

\footnotetext{
X. K. Morin $(\varangle)$

Princeton Writing Program and the Princeton Environmental Institute, South Baker Hall, Whitman College,

Princeton University,

Princeton, NJ 08544, USA

e-mail: xmorin@princeton.edu
}

that agricultural biotechnology will be introduced to new countries around the world including many developing countries as one component of agricultural innovation.

Agricultural innovation, in the broadest sense, potentially can assist in meeting the first of the United Nation's Millennium Development Goals (MGD) - to reduce by half the number of people in extreme poverty and hunger by 2015 [4]. This MGD goal may be partially addressed by focusing on agricultural needs such as sufficient food production, access to water for agricultural purposes, and improved food quality [5]. Agricultural biotechnology has the potential to address some of these needs [6]. Recently, a World Bank report pointed out that science and technology can play a role in helping to improve the food security and alleviation of poverty of the 600 million rural poor in the developing nations [7]. But this report, while acknowledging the great promise of agricultural biotechnology, also acknowledges the controversial nature of agricultural biotechnology through the production of GM food [7]. GM food has become a pawn in debates over trade and globalization and other issues which affect international development [8]. Whether GM crops will play a role in agricultural development, especially in the developing world, seems mixed and dependent upon the public investment in such work [5,7]. China has made a major commitment to investment in government-based agricultural biotechnology and has made much progress, especially in cotton production, and therefore serves as a good case study for the benefits of GM crops in agricultural innovation and development $[8,9]$.

Agricultural innovation must also address climate change and ecosystem services issues. Production of food crops using less energy, less water, and fewer chemical inputs - such as energy-intensive fertilizer - are going to be important in order to reduce carbon emissions [10] and 
Global Area of Biotech Crops, 1996 to 2007: By Crop (Million Hectares)

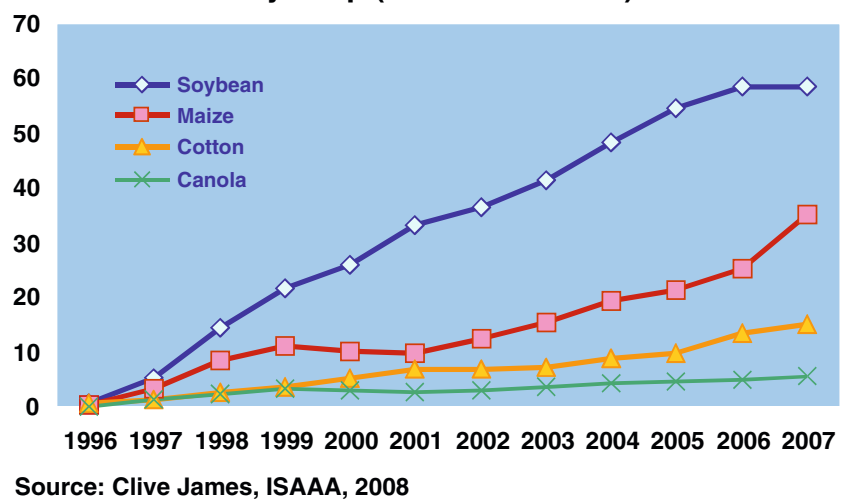

Global Area of Biotech Crops, 1996 to 2007: By Trait (Million Hectares)

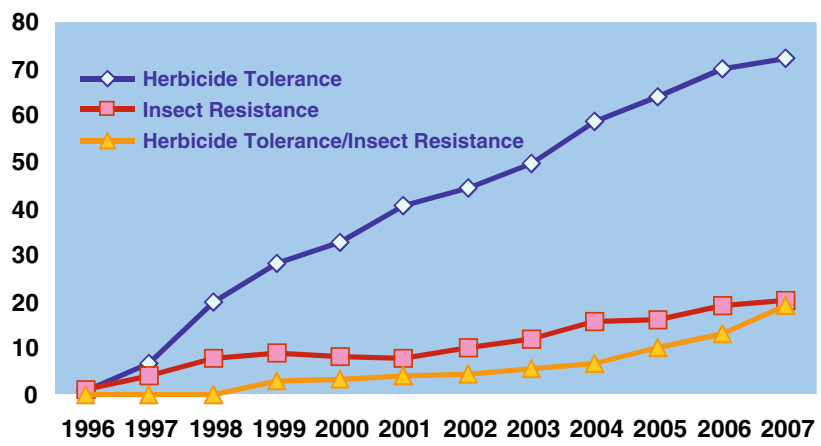

Source: Clive James, ISAAA, 2008

Fig. 1 The rapid adoption rate of genetically modified (biotech) crops from 1996 to 2007 by major crops (top panel) and by two major traits: herbicide tolerance and insect resistance over the same time period (bottom panel). Source [3]

preserve ecosystems and protect human health [11]. Here, again, agricultural biotechnology will most likely have a role. For example, GM corn and GM sugar are currently used as sources for biofuels, and GM soybean is used as a source for biodiesel. Other GM crops (both food and nonfood varieties) are likely to become sources for biofuels/ biodiesel in order to reduce carbon dioxide emissions. Perhaps not surprisingly, this use of GM crops, too, is not without controversy [12]. New issues surrounding climate change and the importance of protecting our ecosystem services will likely emerge over the next ten years. Investment in agricultural research including agricultural biotechnology should play a role in promoting a responsive agricultural sector.

Before some of the controversy over GM food and agricultural biotechnology can be discussed it is important to establish what is generally meant by "GM food and animal feed from crops" and what the worldwide state of GM crops looks like.

\section{What are GM crops?}

GM crops, and the GM food or animal feed derived from them, are developed using the tools of agricultural biotechnology. Agricultural biotechnology, also known as genetic engineering, genetic modification, or transgenic technologies, involves the genetic modification of plant nuclear DNA through the permanent integration of engineered or recombinant DNA (rDNA) sequences using biotechnological techniques. These engineered sequences contain one or more genes and most of the genes come from an organism that is different from the host plant $[13,14]$. Expression of the introduced genes requires a promoter, which is usually the strong cauliflower mosaic virus $(\mathrm{CaM}) 35 \mathrm{~S}$ promoter. A second engineered gene is also included in the DNA to select for transformants. Some transformant selection procedures use genes that protect the cell from antibiotics while others are genes that protect the cell from herbicides. The final rDNA construct is placed into a plasmid's vector and transferred to the plant using Agrobacterium tumifaciensmediated transformation techniques or fired into the plant callus cells using biolistic methods involving plasmidcoated tungsten particles air-propelled by a "gene gun" $[13,14]$. The technique used depends upon the host plant. Monocots such as our cereal crops are more successfully transformed using the biolistic technique. Some percentage of cells will contain rDNA permanently integrated into the host plant's DNA. The transformed plant cells are selected and then grown using plant tissue culture and other propagation techniques before being assessed for the appropriate traits. The location of the DNA integration can have an effect on the transformed plant so detailed analysis of gene expression and plant characteristics are important. Conventional plant breeding is used to ensure the crop has the desired parental characteristics and that the newly introduced trait is, in fact, inheritable [13]. The resulting GM plants are also evaluated for seed viability. The GM crop and the food or animal feed (GM food) resulting from this crop is the product of agricultural biotechnology plus conventional plant breeding.

\section{Examples of GM food from crops}

Fourteen years have passed since the first GM crops were approved for consumption in the United States. The introduction of GM crops into our food supply began in the United States in 1994 when the Federal Food and Drug Administration (FDA) approved the first whole GM food for commercialization: the Flavr Savr tomato [1]. The Flavr Savr tomato was soon followed by other major GM crops: GM cotton (a food crop because it produces cotton seed oil), GM corn (also referred to as GM maize), GM soybean, 
and GM canola, along with other minor crops such as squash [1]. GM crops have been grown ever since. The year 2007, the last year we have data for, proved to have the largest acreage grown to date. According to the non-profit and science-based International Service for the Acquisition of Agri-Biotech Applications (ISAAA), 114.3 million hectares (282.4 million acres) of GM crops were grown in 23 countries [3]. The six largest producers of GM crops by land area, in order, were USA, Argentina, Brazil, Canada, India, and China [3]. GM soybean, GM cotton, GM corn, and GM canola make up the majority of these crops (Fig. 1). Even EU countries such as Spain, France, Germany, Czech Republic, Portugal, and Poland have some, but limited, GM crop acreage [3]. ISAAA claims that over the 12 years from 1996-2007, "2007 marks the first year when the accumulated number of farmer decisions to adopt biotech crops has exceeded 50 million" [3]. In other words, each farmer has had a choice whether or not to grow GM crops, and when tallied over this time period, an estimated 50 million decisions by farmers - on both small and large farms - led to GM crop production. The adoption rate between 1996 and 2007 is a 67-fold increase (Fig. 1) which represents the fastest adoption of a crop technology in modern farming history [3]. Clearly, a large number of farmers see advantages to these GM crops.

GM crops come in many varieties and some examples are given in Table 1. The most common traits are herbicide tolerance and insect resistance (Fig. 1). The engineered DNA integrated into the early GM crops contained a single gene encoding a protein that would confer the trait of interest, usually insect resistance, virus-resistance, or herbicide tolerance. For example, insect-resistance was conferred by the introduction of a Bacillus thuringiensis $(\mathrm{Bt})$ gene which encoded one of the Cry proteins (there are several different Cry proteins each with its own target organism) [14]. Virus resistance was conferred through the introduction of a viruscoat protein [14]. Herbicide resistance to the broad-spectrum herbicide such as glyphosate (trade name Round-Up), was introduced through Agrobacterium-mediated transformation of the CP4 5-enolpyruvylshikimate-3-phosphate (EPSPS) synthetase gene or through mutagenesis of the EPSPS synthetase gene [14]. Recently, "stacked traits" have been introduced into the market; particularly popular in corn are plants that contain multiple insect resistance plus herbicide tolerance. Today, over $35 \%$ of GM crops grown in the USA contain stacked traits [3]. Nutrionally-enhanced and biofortified crops offer the potential for addressing malnutrition $[1,15]$ but further work needs to be done to ensure that these crops can address multiple malnutritional deficiencies using the same crop [15].

Interestingly, GM crops can also be developed for nonfood purposes (Table 1) such as the development of medically important proteins $[15,16]$, and for industrial uses [17]. These types of crop are controversial in that they use food crops to produce non-food products. The Starlink Corn Affair [2] demonstrated the potential problems that can occur when non-human food GM foods are approved. Starlink corn was a Bt corn that was initially approved for animal but not human consumption based on the potential for allergenic responses. Some allergic responses were reported but failed to be confirmed through direct testing [2]. Today, all GM crops must be approved for both human and animals to avoid potential problems. Strict containment protocols have been instituted for field trials and supply chain control has been adopted for the industrial product $[16,17]$. The ability to carefully monitor and test for the presence of non-food GM crops in the food supply will be important in the years ahead to ensure the safety of the food supply $[18,19]$.

\section{Why the controversy?}

The controversy of GM foods continues to flair up despite more than 14 years of experience with these crops. Attempts to address the controversy has led to limited access of GM foods to certain agricultural markets such as the EU, and the labeling of GM foods in many, but not all, countries. For example, the United States does not have GM food labeling. Although labels can be useful, they rarely provide sufficient information to be truly informative (see McHughen in Ref. [1]). Additionally, there are no international labeling standards for GM foods despite efforts through the UN's Food Standard Codex Alimentarius. This reflects a division over the need for labeling in the first place. To date, there have been documented adverse health and environmental effects [20] and documented benefits from the introduction of this technology (for an example see [1,9]). The risks associated from eating approved GM foods appears to be low, especially compared with other food safety issues such as food poisoning, but so far no worldwide consensus has emerged regarding the health and safety of all GM crops. Each GM crop is now considered on its own merits based on the types of modifications it has undergone. Most importantly, early cataclysmic predictions appear not to have come true, suggesting that these GM crops are not particularly different from conventional or hybrid crops.

Social factors appear to play a role in the rejection of GM food. One such factor is the issue of control over this technology. This lack of control is largely expressed as fears over consumption of GM crops without permission. For example, one might fear non-GM food contamination by GM foods, or fear food contamination by non-food GM crops or unapproved GM food. At the heart of this fear is the frustration at being unable to independently verify the source 

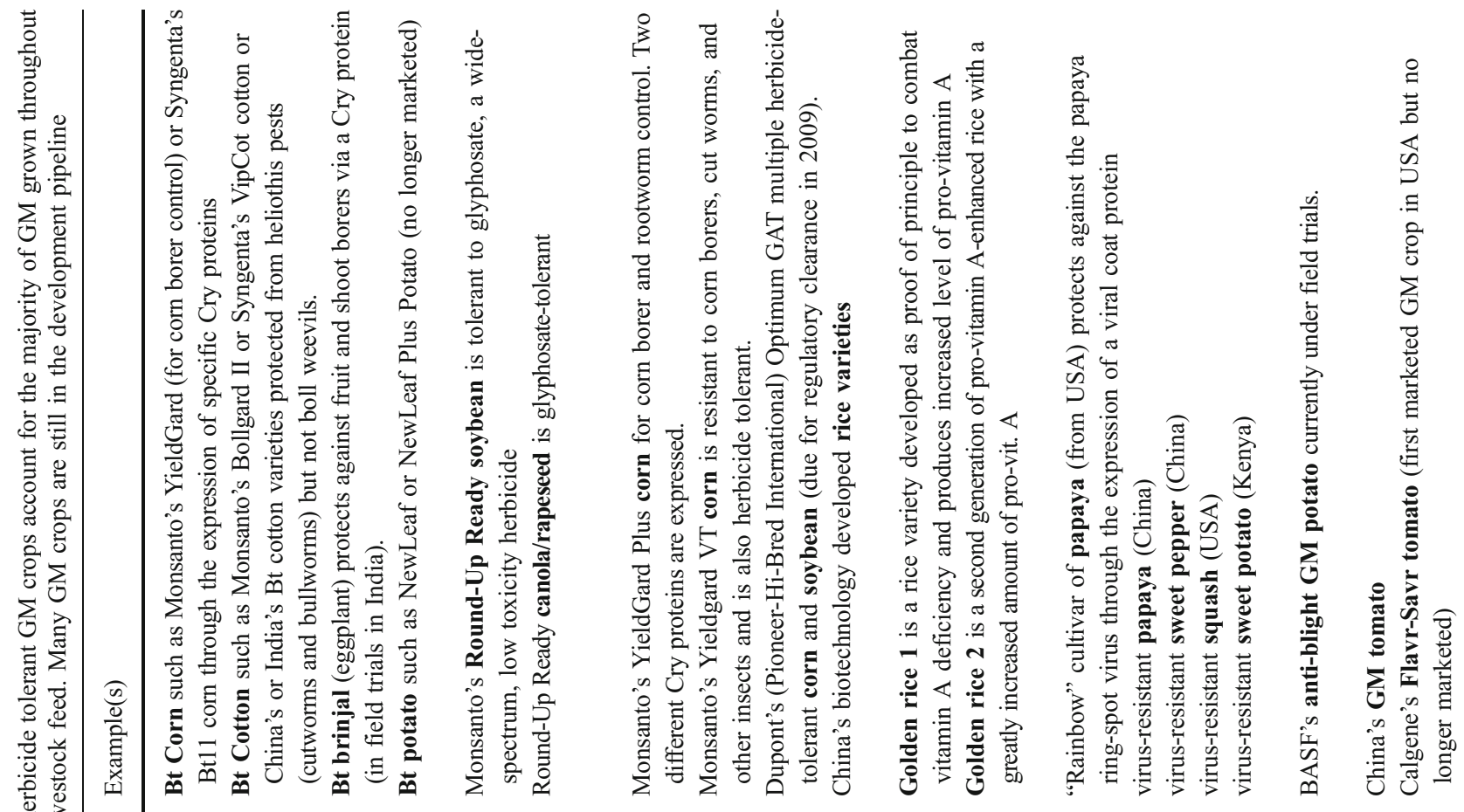

는

है

焉

跑

过

$\stackrel{8}{5}$

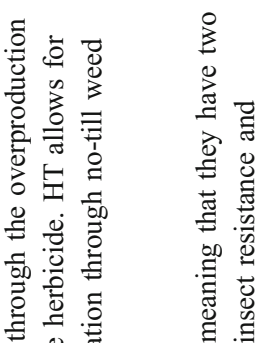

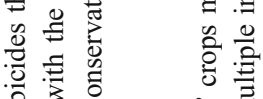

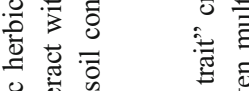

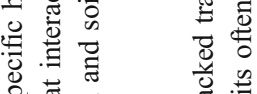

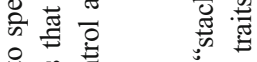

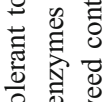

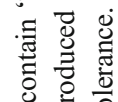

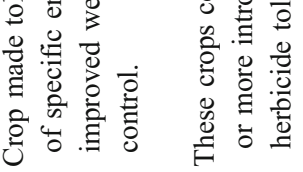

है

章

홍

용ㅇ

倠

䇂

类

है

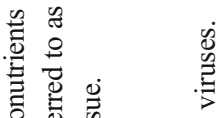

定花

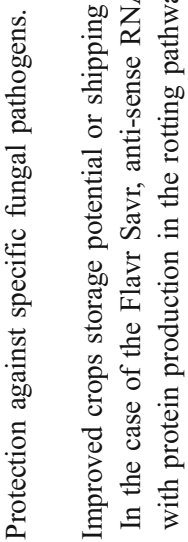

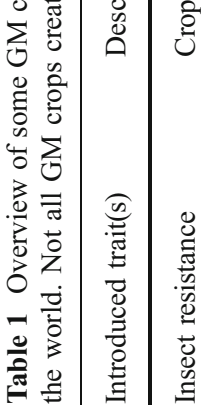

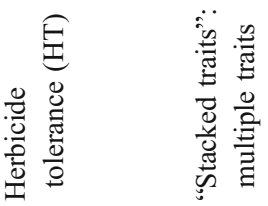
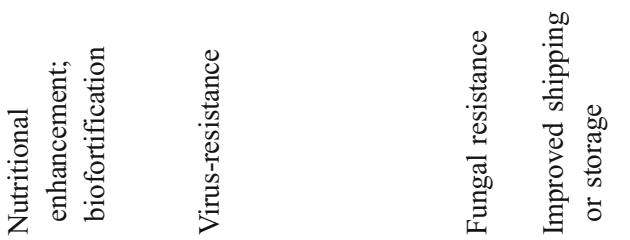
of the food; in other words losing control over knowing what one eats. This fear may be addressed through labeling if it is available and as long as post-market testing occurs.

Another area where control is an issue is over the use of GM seeds. GM seed companies are mostly owned by multinational agrichemical corporations and many constraints are placed on the use of these seeds. Lack of control over GM seeds uses has influenced some farmer's reactions to GM foods if strong intellectual property rights or technology use agreements exist [1, 2]. With GM crops, farmers must buy their seeds and may no longer plant seeds they collect. This is not unusual for farmers who have used hybrid seeds, but might be unusual to others, especially those who have collected seeds and done their own selective breeding.

These fears over GM food and GM seeds address our inability to individually control this technology or the content of our food supply. Other factors that lead to the rejection of GM crops include a mistrust of scientific arguments, rejection of scientific advances due to the arrogance of science and business leaders, a mistrust of corporations due to their overly zealous hype surrounding early biotech crops and corporate profit-motives, and a heightened aversion to risk, especially when the current food production system appears to be working well [1]. As you can see, there are many different reasons. Rejection of the earliest GM crop, the Flavr Savr tomato, was also based on the poor quality of the product itself [21], which seems like a reasonable outcome in a competitive marketplace.

A newer argument offered by some pro-organic farming groups is that supporting GM crops continues to support or "reinforce an outdated mode of [industrial] agriculture" [22]. Here the group is particularly concerned about the ability of GM crops to be grown in an environmentally sensitive manner, especially with respect to energy use and climate change [22]. These recent arguments may play into identity politics as people who support organic agriculture will often reject GM crops outright since the two systemsorganic farming and industrial farming-are considered incompatible. Pro-organic groups have been particularly effective in supporting legislation requiring labeling of GM foods, not for promotion of GM food, but for the avoidance of GM food. They have also promoted more sustainable agricultural systems [2].

Opposition arguments against GM foods can also be motivated by political, ethical, and, sometimes, scientific reasons. Political opposition to GM crops is embedded in some countries and can play a role in national or EU elections. Ethical considerations can center on the fear that we are overstepping a moral limit that guides our tinkering with nature [1]. While crossing plants seems "natural", genetic modification using agricultural biotechnology seems "unnatural" to some because it appears to cross a moral limit. There 
is a fear that we will not know the outcome of our work until a catastrophe is upon us [1]. In doing this, we question our hubris in the application of this agricultural biotechnology [1]. This ethical argument falls into concerns over the process used to produce the GM crop.

The process by which these plants are made is one source of the controversy over GM crops and food, especially with regard to concerns about unintended health or environmental consequences $[1,2,13]$. The initial newness and unfamiliarity with genetic engineering in plants in the early 1990s led to a precautionary approach by some but not all [1]. Advocates and opponents of the GM technology have locked horns over whether it is the process (genetic modification) or the end-product (the GM crop containing the new trait) that is most important to consider when assessing the potential risk. Although some advocates of agricultural biotechnology argue that gene transfer by transformation is just an evolution of previous plant breeding techniques (for example see Dawkins in Ref. [1]) this may not be a valid argument because there are significant differences in the changes that can occur at the DNA level.

Conventional plant-breeding involving selection of plants for specific traits has utilized both intraspecies and interspecies crosses, plant hybrid production, chemical and $\mathrm{X}$-ray mutagenesis, embryo rescue, and other techniques $[12,13]$. In these cases, the whole plant genome was involved and genetic changes could occur on the whole genome, chromosome, and/or gene level. Chromosome numbers and chromosome parentage could be altered, and chromosome translocations and gene duplications occurred [13]. Only recently though chromosome maps and the sequencing of plant genomes have we come to a better molecular understanding of the genetic make up of our cereal crops. Some small and large genetic changes have led to favorable crop traits. These genetic changes achieved through plant breeding - which some consider a natural process - appear to be potentially more significant than the introduction of single or multiple genes to specific locations in the plant genome via gene transformation. Therefore, the processes of more conventional plant breeding seem to allow for the potential for larger genetic changes compared with genetic engineering. However, given that we have eaten the food resulting from this level of genetic changes via plant breeding, it suggests that the process might not be as important as one might imagine, since the edibility of the food and the ability of the plant to grow and survive to yield sufficient grain are important selected traits.

Genetic modification through transformation leads to an "event" that introduces the engineered DNA plants' genome. There can be changes to surrounding gene expression but the scope of the changes can be selected more specifically based on the health of the transformed plant. Additionally this event must be characterized through DNA sequencing, analysis of gene expression, and protein production (where appropriate); other changes to the composition of the plant must be reported to regulatory authorities and are important in risk assessments and regulatory approval [1]. For example, under US regulatory systems "substantial equivalence" is a concept that is used to evaluate GM crops. This means that the plant is considered to be the same except for the additional trait that has been introduced. If the trait can confer selective fitness to the plant, then ecological considerations also need to be taken into account if there is the possibility of cross-pollination with wild relatives.

When scientists are asked to consider the longer term environmental and health consequences of this technology fewer answers exist because our experience is limited. Scientists can make predictions, but research must be done to consider issues on a longer time-scales. These uncertainties also lead to controversy over the use of GM crops $[1,2,13]$. Health issues are important to consider [14], as are ecological issues. Health issues were so important that a US National Academies of Sciences report was issued in 2004 to offer guidance [14] and industry takes it quite seriously [17]. Ecologists seem particularly concerned about the long-term consequences to the environment, biodiversity, and nontarget organisms. Studies are now being reported that will help us to understand many of these issues more fully. It would behoove us to fund studies that address their concerns [13]. Analytical chemists can assist the ecologists by providing them with tools that allow them to look at, for example, the potential gene flow to weeds from GM crops, assess fitness advantages in plants, or to look at changes in microbial soil communities as a way to evaluate associated environmental changes.

These, and other challenges to the wisdom of using GM foods are easy to find in media articles, on websites, and in numerous blogs. They are worth exploring in order to fully understand the opposition to GM crops; equally important is exploring the scientific literature in more detail to look for the benefits and risk of GM foods. Be aware that small groups of individual leading organizations can often sway large numbers of people for and against GM significantly in some places. For example, during the late 1990s and early 2000 opposition groups such as Greenpeace and Friends of the Earth learned how to capture worldwide media attention and are able to generate fear in consumers and politicians alike, often through their emotive and sometimes misleading or flatly incorrect statements $[1,2]$. Their ability to capture media headlines and political attention continues today.

Different social, political, and ethical attitudes to GM foods are not easily addressed or resolved on the basis of the events of the last couple of decades. At times it appears that GM foods have become pawns in larger conversations regarding the governance of our world. Good public policy and regulatory systems can help smooth out differences 
over GM foods but often gaps in policy or regulations cause issues to remain unresolved such as is seen in the EU. Addressing issues of harmonization of regulations, intellectual property rights, and trade policies across international borders can also be helpful but may not be enough, and, in some cases, may cause additional conflicts. Sometimes scientific evidence can help justify the safety of GM crops if it is presented by independent bodies with no apparent agenda; but independent groups are hard to find. More importantly, science cannot resolve some differences because addressing the conflict involves exposing each stakeholder's differing values and priorities. For example, those unsure of GM technologies have often chosen a precautionary approach while others have been more bold in their support [1]. These two approaches represent differing values and priorities. Those in the USA that support GM technologies have supported intellectual property rights as a means of agricultural innovation and economic development promoted by the private sector. China has taken a somewhat different approach and used public funds along with collaborations with private companies to develop its GM crops. Precautionary approaches reflect the opinion that moving too rapidly might lead to unintended and potentially irreversible changes. Since each stakeholder group will likely have different values, priorities, stakeholders, assumptions, and issues behind their wariness or support of GM foods [1], it is no surprise that the GM food debate remains a complicated one to resolve.

\section{Future possibilities}

It is important to acknowledge that science and technology alone cannot fully mitigate the GM food debate, but science and technology can play important roles, and may open up new opportunities. Because it looks as if GM foods are here to stay [3], what we must continue to improve is a food system that allows for the production and sale of both GM foods and non-GM foods. Ideally, this food system would allow for both GM and non-GM foods to easily coexist anywhere in the world. Achieving this goal is where the analytical chemists/biochemist can help. Co-existence of both food types requires that we be able to follow GM crops throughout the food system - from "farm to fork" - and verify the absence, limited presence, or presence of GM food in the non-GM food stream. Additionally, analytical chemists/biochemists can monitor, and assist in ensuring, that only those GM crops that are approved for distribution enter either food stream. Finally, analytical chemists/biochemists can continue to develop the tools we need that can help us to identify and reduce any potential harm these crops might cause.

Currently many methods exist for GM food detection. These methods usually focus on detection of the rDNA or newly expressed protein. These methods range from DNA-based methods such as PCR, RT-PCR, and DNA microarray experiments, to protein-based methods based on gel-electrophoresis and immunological assays such as ELISAs. Additionally, HPLC, GC-MS, near-infrared (IR) spectroscopy, and biosensors, among others, have been explored $[14,18]$. In some cases these detection methods are qualitative while others are quantitative $[14,18]$. Some methodologies are too expensive for routine work or are illsuited to rapid field sampling. A good overview of methodologies and challenges behind GM crop detection can be found elsewhere $[14,18]$. Where analytical chemists/ biochemists may be most helpful might be $[14,18]$ :

- designing faster, and cost-effective, methods for specific and sensitive detection of one or multiple GM crops;

- designing faster, and cost-effective, detection methods for use in the field or at the grain elevator;

- developing or enhancing current high-throughput methods to distinguish between varieties in an economically feasible manner;

- further developing useful methodologies that will assist industry and government regulators in meeting all regulatory requirements;

- developing GM crop reference materials and standards for validation purposes at accredited laboratories;

- developing reliable methods for quantification of crops with single or multiple gene inserts;

- developing new methods to detect compounds or biochemical changes that might lead to potential health effects, such as allergenicity, anti-nutrients, toxicity, and immunological or morphological changes;

- designing tools to assess the environmental impact of GM crops;

- developing tracking methodologies that could be incorporated into the plant (e.g. a plant DNA ID tag);

- developing appropriate methods for assessing changes to plant composition and metabolism that occur due to genetic modification; and

- developing methods to efficiently draw upon, and contribute to, plant genomic, proteomic, and metabolomic databases including GM detection databases.

There are probably other needs that exists which are not listed above. Applications of these needs could lead to job possibilities in industry and in government regulatory agencies, testing laboratories, universities, and possibly in organizations that monitor GM foods. Clearly, there is a role for analytical chemists/biochemists in the GM food arena.

New GM crops will continue to come to market. The private sector, some government agencies, agricultural research centers, and some universities are currently researching and developing new GM food crops and GM crops for other purposes. These crops are currently under- 
going, or will soon undergo, field trials. Their success during these field trials, and in their testing, will-in partdetermine whether they will be submitted for regulatory approval. Not all GM crops will make it to market but those that do will need to be monitored and their impact assessed. Despite opposition, the future looks bright for many GM crops and being able to successfully track and assess them will likely mitigate the GM foods debate. New possibilities for many types of GM food could be the future. Agricultural innovation might finally move beyond providing commodity crops and fulfill the early promises that GM foods will help feed the hungry and malnourished of our growing world.

Acknowledgements I would like to thank Sylvia Daunert and Sapna Deo for useful feedback. I am also indebted to my students for teaching me, and for showing me the need to discuss the GM foods debate. I would also like to thank the Princeton Writing Program and the Princeton Environmental Institute for their financial support.

\section{References}

1. Ruse M, Castle D (eds) (2002) Genetically modified foods: debating biotechnology. Prometheus Books, Amherst, NY

2. For a fairly balanced overview, see: Harvest of Fear, A NOVA/ Frontline Special Report. Public Broadcasting Service, Jon Palfreman, writer, director and producer, 2001. Documentary Website. http://www.pbs.org/wgbh/harvest/. A more bias, and largely anti-GM foods view is provided in the documentary Future of Food, Deborach Koons Garcia (Director), Lily Films, Mill Valley, CA, 2004

3. James C. ISAAA Brief 37-2007: executive summary global status of commercialized biotech/GM Crops: $2007 \mathrm{http}: / /$ www.isaaa.org/ resources/publications/briefs/37/executivesummary/default.html (Accessed June 29, 2008)

4. The UN Millennium Development Goals. http://www.un.org/ millenniumgoals/ and references therein such as the Millennium Development Goals Report 2007 (mdg2007.pdf). (Accessed July 11, 2008)

5. Conway G (1998) A doubly green revolution: food for all in the 21st century. Comstock Publishing Associates, Cornell University Press, Ithaca, NY

6. Acharya T, Daar AS, Singer PA (2003) Nat Biotechnol 21:1434 1435

7. World Development Report (2008) Agricultural for development. The World Bank, Washington DC

8. Heusing J, English L (2004) AgBioForum 7:84-95

9. Huang J, Hu R, Fan C, Prey C, Rozelle S (2002) AgBioForum 5:153-166

10. Socolow R, Hotinski R, Greenblatt JB, Pacala S (2004) Emissions Environ 46:8-19
11. Ecosystems and Human Well Being: Synthesis, Millennium Ecosystems Assessment, World Resources Institute, Island Press, 2005. Also accessible via http://www.millenniumassessment.org/

12. Searchinger T, Heimlich R, Houghton RA, Dong F, Elobeid A, Fabiosa J, Tokgoz S, Hayes D, Yu T-H (2008) Science 319 (5867):1238-1240 (29 Feb) doi:10.1126/science.1151861

13. Pfeiffer TW (2003) From classical plant breeding to modern crop improvement. In: Crispeels MJ, Sadava DE (eds) Plants, genes and crop biotechnology, chap 14. 2nd edn. Jones and Barlett, Sudbury, MA

14. Safety of Genetically Engineered Foods: Approaches to Assessing Unintended Health Effects. National Academy of Sciences, National Academies Press, Washington DC, 2004. http://www. nap.edu/openbook.php?record_id=10977 (Accessed July 14, 2008)

15. Golden Rice Project http://www.goldenrice.org/. A more traditional plant breeding approach to biofortification is being taken by Harvest Plus http://www.harvestplus.org/(Accessed July 14, 2008)

16. Ventria Biosciences, Inc. http://www.ventria.com/ (Accessed July 14, 2008)

17. For example see BASF's Amflora Potato for the production of potato starch for industrial uses http://www.corporate.basf.com/en/ stories/loesungen/amflora/start.htm?id=V00-Sb8.zCb-4bcp (Accessed July 14, 2008)

18. Ahmed FE (ed) (2004) Testing of genetically modified organisms in food. Food Products Press, Howarth Press, New York

19. Martens MA (2000) Int Arch Occup Environ Health Jun 73 suppl: $\mathrm{S} 14-\mathrm{S} 21$

20. Smith JM (2007) Genetic roulette: the documented health risks of genetically engineered foods. Yes! Books, Fairfield, IA

21. Marineau B (2001) First fruit: the creation of the Flavr Savr tomato and the birth of genetically engineered food. McGraw-Hill, New York

22. Gordon does 'a Tony': falls for GM hype. Press release 06/19/2008 (version 3). UK Soil Association. http://www.soilassociation.org/web/ sa/saweb.nsf/librarytitles/253B6.HTM (Accessed July 16, 2008)

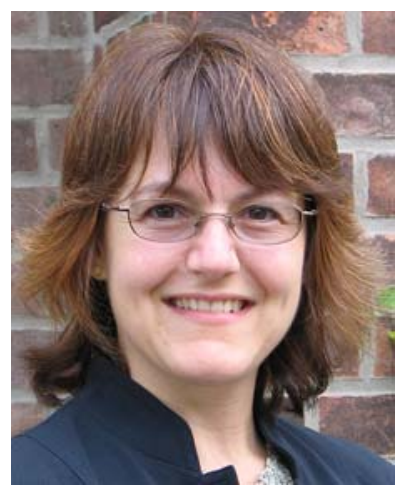

\section{Xenia Morin}

is a plant biochemist by training and currently holds the position of lecturer in the Princeton Writing Program and the Princeton Environmental Institute at Princeton University. She is interested in the interplay between science, technology, and society, particularly in terms of agriculture and food production. She is concerned with a range of issues, from the acceptance of genetically modified foods to the emergence of the organic, local, and slow food movements. She also explores issues such as how to feed the world, food security, hunger, and malnutrition, environmentalism and sustainability in agriculture, and the production of biofuels. 